\title{
An Online Potato Pedigree Database Resource
}

\author{
R. van Berloo • R. C. B. Hutten • H. J. van Eck • \\ R. G. F. Visser
}

Received: 17 March 2007 / Accepted: 7 August 2007/

Published online: 12 October 2007

(C) EAPR 2007

\begin{abstract}
At the Laboratory of Plant Breeding of Wageningen University, a large amount of pedigree data on current and historic potato cultivars and progenitors has been collected over many years. The sources and reasons for collection of these data are discussed. To allow others to use this data set for their own purposes, we have created a Web-accessible interface that allows querying of these data, e.g., for the ancestry of a cultivar of interest. This Web interface was recently extended and improved to allow users to create reports and dynamically created pedigree-tree images. Availability of this resource and the options provided by the new Web interface are presented.
\end{abstract}

Keywords Breeding history $\cdot$ Database $\cdot$ Pedigree $\cdot$ Potato $\cdot$ Solanum tuberosum . World Wide Web
Abbreviations
CoC coefficient of coancestry
LD linkage disequilibrium
PHP PHP hypertext preprocessor
PVY Potato virus $Y$

\section{Introduction}

Pedigree information has always been a useful source of information for breeders. To avoid the pitfalls of a narrow genetic base, pedigree information has historically been

R. van Berloo • R. C. B. Hutten $(\bowtie) \cdot$ H. J. van Eck • R. G. F. Visser

Laboratory of Plant Breeding, Wageningen University, PO Box 386, 6700 AJ Wageningen,

The Netherlands

e-mail: ronald.hutten@wur.nl

Present address:

R. van Berloo

Keygene NV, Agro Business Park 90, Wageningen, The Netherlands 
used to assess relatedness and to select promising parental combinations. The increasing amount of information that has become available on individual plant genotypes through the advent of genomics has reduced the attention given to pedigree data, but pedigree data remain an important and relevant source. Contemporary approaches identifying genetic factors underlying (quantitative) traits in (presumed) unrelated germplasm, such as linkage disequilibrium (LD) or association mapping (Rafalski 2002; Gaut and Long 2003), have shown that the power of these analyses can be improved if we are able to include relatedness between genotypes in the analyses (Yu et al. 2006; Malosetti et al. 2007). Information on relatedness in a set of genotypes, for which the origin is unknown, can be obtained using similarity estimates and genetic distances. Molecular markers can be used to generate data that reflect DNA sequence differences between genotypes (Yu et al. 2006). Detailed pedigree information, when available, can provide a measure for relatedness as well. Classical genetic estimates of the coefficient of coancestry (CoC) (Falconer and Mackay 1996) can be obtained from pedigree analysis and may provide alternative or additional measures that quantify relatedness among genotypes. Pedigree-derived matrices of relatedness estimates can thus be used in association or LD mapping analyses (Simko et al. 2004).

Another application of pedigree information is to assign names to resistance genes and to trace down their identity. The following example on Potato virus Y (PVY) resistance genes is derived from the thesis work by Song (Song 2004; Song et al. 2005). Initially, three virus resistance genes were mapped on potato chromosome 11. These were $R y_{\text {sto }}$ (Brigneti et al. 1997), $R y_{a d g}$ (Hämäläinen et al. 1997) and $R a_{a d g}$ (Hämäläinen et al. 1998). The position of $R y_{\text {sto }}$ was verified and assigned to potato chromosome 12, where pedigree information provided additional evidence for being identical-by-descent in various German cultivars (Song 2004; Song et al. 2005). The $R y-f_{\text {sto }}$ gene (Flis et al. 2005) must be identical to the $R y_{\text {sto }}$ gene (Song 2004) because of the similar set of potato cultivars studied and carrying the resistance gene. The resistant parent I-1039 used by Brigneti et al. (1997) has Solanum phureja and S. edinense in its pedigree. Recently, another PVY resistance gene, $R y_{c h c}$, was mapped to the distal end of potato chromosome 9 (Sato et al. 2006). This example shows the joint relevance of pedigree information and map position to identify and assign the correct locus name and to differentiate between various loci with indistinguishable phenotypes.

Pedigree information is also highly relevant for understanding the differential interactions between potato genotypes and their pathogens. Wart-disease pathotypes, for example, are characterized using many and different potato cultivars. Each country uses a different set of differentials (Baayen et al. 2006). Closer inspection of the relatedness of these differentials through pedigree information reveals a tremendous redundancy in this list, with full sibs or straight descendants that pass on the same resistance from, for example, cv. Jubel (1908), to cv. Hindenburg (1916), to cv. Aquila (1942), to cv. Schwalbe (1956), which is illustrated in Fig. 1.

Although pedigree information can be considered static, there is often no central repository available. Plant breeders and researchers usually record the breeding history of their material, but availability of this information is in general limited. Agencies involved in cultivar testing for admission to national lists record the parentage of genotypes, but only for the small subset of genotypes submitted as new 黑 Springer 


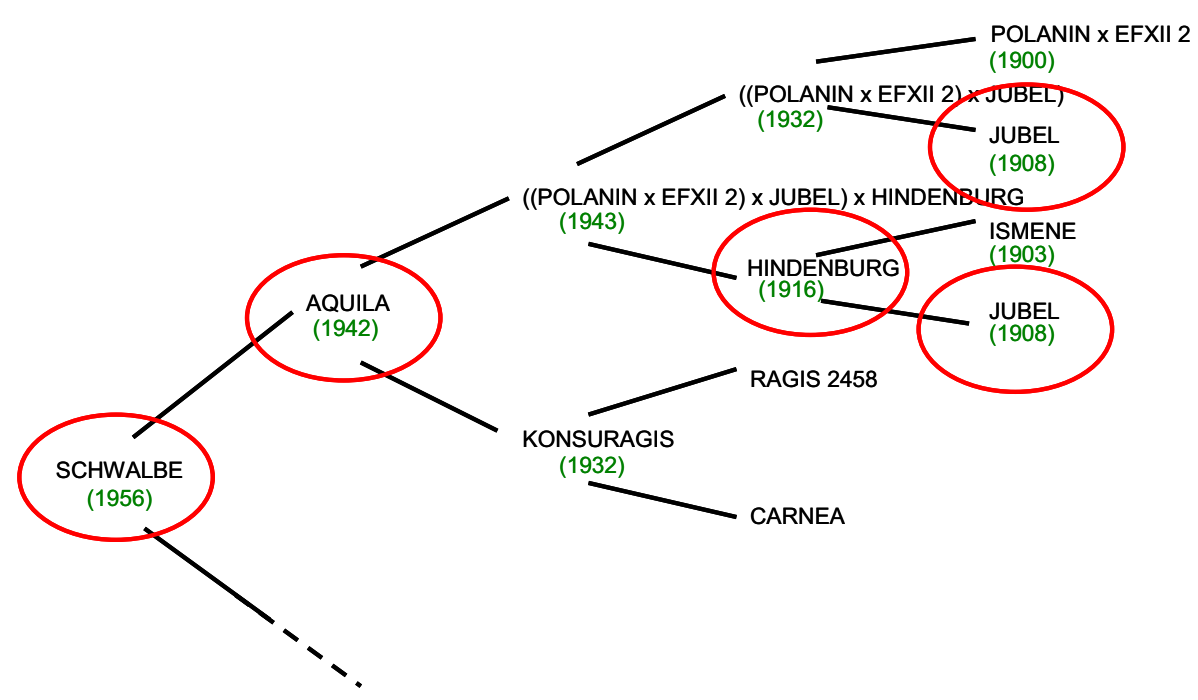

Fig. 1 Part of the pedigree tree of the potato cultivar Schwalbe, showing the path of descent of wartdisease resistance

cultivars. Nevertheless, if the records of these agencies are public, they can be a good starting point when hunting for more information on the breeding history of cultivars. In general, we can state that the collection and update of a more complete set of pedigree data from dispersed sources is not an easy task. An example of the construction of a central pedigree database dealing with oat pedigrees was described by Tinker and Deyl (2005). In this paper, we describe the development, data collection, curation, and features of a Web-accessible pedigree database for cultivated potato genotypes.

\section{Materials and Methods}

Aim and Sources of Information of the Wageningen University Potato Pedigree Database

The Wageningen University potato pedigree database aims to contain pedigree information for all released cultivars worldwide and subsequently all progenitors that were used to breed these cultivars. The database had its starting point in the 'Geniteurslijst voor aardappelrassen' (Hogen-Esch and Zingstra 1954, 1957, 1962, 1969, 1971/1972, 1973/1974; Zingstra and Scheijgrond 1975/1976, 1977/1978, 1979/1980; Zingstra 1981/1982; Joosten and van der Woude, 1985; Joosten 1988, 1991). In addition, pedigree data from several breeding companies were merged, and this list was further extended using historic books and monographs on potato cultivation and breeding (e.g., Busch 1889; Salaman 1926; Diehl 1938; Clark and Lombard 1946; Schick and Klinkowski 1962; Pushkarnath 1964). Often, these monographs derived their information from early breeders, such as G. Veenhuizen, W. Richter, and others, printing catalogues or price lists with cultivar names and descriptions of the most important traits. 
Over the course of 16 years, the pedigree database was expanded through diligent study of a wide variety of sources such as breeding records, scientific literature (e.g., for many decades the American Potato Journal has published descriptions and pedigree information of newly released cultivars), Web resources, variety lists, personal communications, and last but not least, publications of collected pedigree information (e.g., Swiezynski et al. 1997). In this way, the pedigree database has grown from an initial modest repository of several hundreds of potato cultivars and progenitors to a large data set containing pedigree and breeder details of over 7,000 potato genotypes from as many countries as possible. Additionally, a separate unpublished database records pedigree information for prebreeding material, progenitors, and unreleased breeding genotypes. Once genotypes from this second data set are commercially released as cultivars (or occur in their pedigree), data are added to the published cultivar pedigree database.

\section{Name Uniformity and Ambiguities}

In addition to the collection of data, great care was taken to correct errors and standardize pedigree data as much as possible. When different pedigree data for the same genotype are found, all acceptable possibilities are listed. The occurrence of synonyms (e.g., cv. Eersteling for cv. Duke of York, cv. Palogan for cv. Allerfrüheste Gelbe, cv. President for cv. Paul Kruger) and differences in the reproduction of unusual characters from non-Roman languages are addressed. Translation of Russian cultivar names from Cyrillic script, for example, will easily introduce the ambiguity of the letters $v$ and $w$ in Roman script. Finally, we corrected for typing or writing errors that caused identical cultivars to be represented by different names. More problematic are cases in which an existing cultivar name was reused one or more times. This occurred in general because breeders were not aware the name was already used or in use, but more recently, predominantly German breeders have been fond of reusing names of old and famous cultivars (e.g., cv. Pepo, cv. Deodara). To illustrate this problem, we show in Table 1 all known pedigree information of the cultivar Alma. There is no real solution to the ambiguity created by reusing cultivar names, but in many cases, the context in which a cultivar name is used can still provide sufficient leads for an "educated guess" on which of the homonymous cultivars is most plausible. When breeder codes of released cultivars show up in pedigree data they are replaced, if possible, by the cultivar name. The breeder codes of cultivars remain stored in one of the database fields.

Table 1 Overview of all pedigree information available in the database for cv. Alma. This example illustrates the ambiguity present in collected pedigree information, which may partially be resolved by not only taking into account a cultivar's name but also the year of release and geographic origin

\begin{tabular}{llll}
\hline Cultivar & Year of release & Country of origin & Pedigree \\
\hline Alma & 1904 & Germany & Early Sunrise $\times$ Erste Von Fromsdorf \\
Alma & 1928 & Netherlands & Excellent $\times$ Preferent \\
Alma & 1978 & Czechoslovakia & Oda $\times$ Schwalbe \\
Alma & 1984 & Austria & SL $63 / 63 \times 368 / 61$ \\
\hline
\end{tabular}


Data Accessibility and Presentation

Until 2001, the potato pedigree database was not accessible to a wider public. On request, individual records were extracted and details provided via direct personal contact, but the impact remained limited. In 2001, the Laboratory of Plant Breeding of Wageningen University decided to make the pedigree data (at that time containing close to 6,000 genotypes) available via its Web site. A first Web interface was created in that same year. This interface provided basic look-up and search functionality on (part of) a cultivar name. In addition to the search for cultivar progenitors, this online database was extended with a search for offspring of cultivars. Query results consisted of the direct parentage of a genotype and, where possible, individual progenitors were presented with a direct hyperlink to a search for their pedigree.

The Peditree software (van Berloo and Hutten 2005) allowed us to produce static pedigree images of pedigree trees for genotypes in the database. From 2003 on, links were provided to these images as part of the query results. Due to the ambiguity present in the database, genotype names could not be used as unique identifiers, so anonymous identification (ID) numbers were used instead. As a result, for each (yearly) database update, all static pedigree images had to be redone. As this is a very cumbersome and time-consuming exercise, availability of pedigree images kept lagging behind database contents.

A solution to this problem was found in the creation of more advanced scripts for database querying. The scripting language PHP (http:/www.php.net) was used to implement algorithms, which recursively query the database (up to a certain predefined depth) and dynamically create a conventional pedigree-tree diagram. The main advantage of this solution is the flexibility with regard to data updates and additions. Any change in the data is instantly reflected in the pedigree images. Furthermore, by creating images at the moment a query is performed, we are able to add navigational layers on top of the image that thus allow further "point-and-click" questioning of the database. The 2007 database update was used to launch the new potato pedigree database Web site, which includes these new PHP scripts for the dynamic creation of pedigree images.

\section{Results}

\section{Database Development over Time}

Approximately 16 years ago, the pedigree database started with pedigree data on 1,600 genotypes. Since then, the amount of available information has grown considerably, reaching 7,353 genotypes in July 2007. Database expansion can be read from Fig. 2, which shows the number of genotypes with pedigree information in the database since 1991. On average, the database growth amounts to 350 genotypes with pedigree details each year. Part of this growth is related to newly released cultivars, but the majority of data additions stem from other resources and lead to further clarifications of pedigree data on older cultivars for which no data had been available before. 


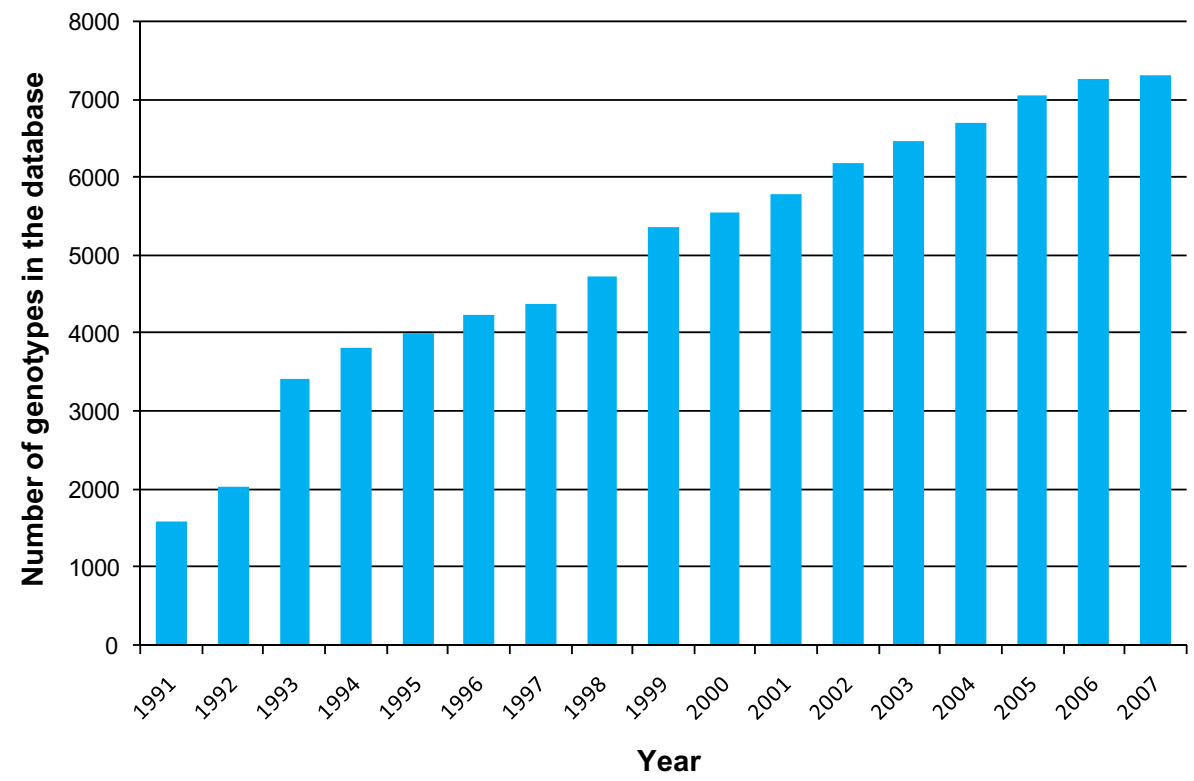

Fig. 2 Growth of the number of genotypes with pedigree data in the database over time

\section{Origin of the Pedigree Records}

In the early days, the potato pedigree database mainly contained pedigree records on cultivars developed in the Netherlands. But over the years, records from other countries were added in large numbers. Currently, the database contains pedigree data on genotypes that originate from 68 countries. Table 2 gives an overview of the countries with the largest contribution of genotypes to the pedigree database today. The Netherlands are still the largest contributor of genotypes with known pedigree data, but many other counties with important potato resources are also very well represented.

Table 2 Top-ten list of countries of origin with regard to number of genotypes with pedigree information in the pedigree database

\begin{tabular}{lc}
\hline Country & Number of cultivars in the database \\
\hline The Netherlands & 1,501 \\
Germany (incl. former BRD and DDR) & 1,233 \\
USA & 1,040 \\
United Kingdom & 697 \\
Russia and former Soviet Union & 465 \\
Poland & 363 \\
France & 244 \\
Czech Rep., Slovakia + former Czechoslovakia & 148 \\
Canada & 142 \\
Japan & 128 \\
58 other countries or unknown origin & 1,357 \\
\hline
\end{tabular}


For most cultivars in the database, a year of release is known. The oldest dated entry is cv. Bremerroode, which is dated before 1770 and which is close to the first descriptions of potato as a cultivated crop (Salaman 1949). We aggregated the data in the database based on the year of cultivar release. An overview of all 4,532 cultivars with information on their year of release is given in Table 3 . Most cultivars date from the second half of the twentieth century, which can partly be explained by the better availability and accessibility of breeding records, but above all, it reflects the increased efforts in potato breeding over the last 5060 years.

At the time of writing, the database contained sufficient data to allow retrieval of pedigree records that go up to 20 generations deep in at least one of the branches (e.g., the $2004 \mathrm{cv}$. Biogold). Such large pedigrees then contain several hundreds of unique ancestors.

\section{Pedigree Database Web Interface}

\section{Version 1 of the Online Potato Pedigree Database}

The first Web-accessible potato pedigree database was made public in 2001 via the URL: http://www.dpw.wau.nl/pv/query.asp. This Web site has seen a steady increase in popularity since it was launched. The growth in the number of queries over time is shown in Fig. 3. We can roughly observe a linear trend, although the trend appears to reach a plateau in 2005. We think, however, that the slightly reduced number of queries in 2006 is only a temporary effect, caused by the redesign of the Wageningen University Web site in January 2006, which caused reduced visibility of the Web site of the Laboratory of Plant Breeding for some time. Also, recent visitor counts (up to July 2007) show a clear growth of interest.

\section{Version 2 of the Online Potato Pedigree Database}

Interest in the database assured us that the resource served a need. We also made progress in software and data-mining algorithm development in a related project (van Berloo and Hutten 2005). Furthermore, we faced an expected discontinuation of the existing Web server that hosted version 1 of the database. These elements together

Table 3 Distribution of cultivars present in the potato pedigree database with regard to the year of release

\begin{tabular}{lc}
\hline Time period & Number of genotypes in the database \\
\hline$<1800$ & 4 \\
$1800-1825$ & 10 \\
$1825-1850$ & 16 \\
$1850-1875$ & 87 \\
$1875-1900$ & 368 \\
$1900-1925$ & 310 \\
$1925-1950$ & 528 \\
$1950-1975$ & 1,147 \\
$1975-2000$ & 1,763 \\
$>2000$ & 299 \\
\hline
\end{tabular}


Number of unique database visitors

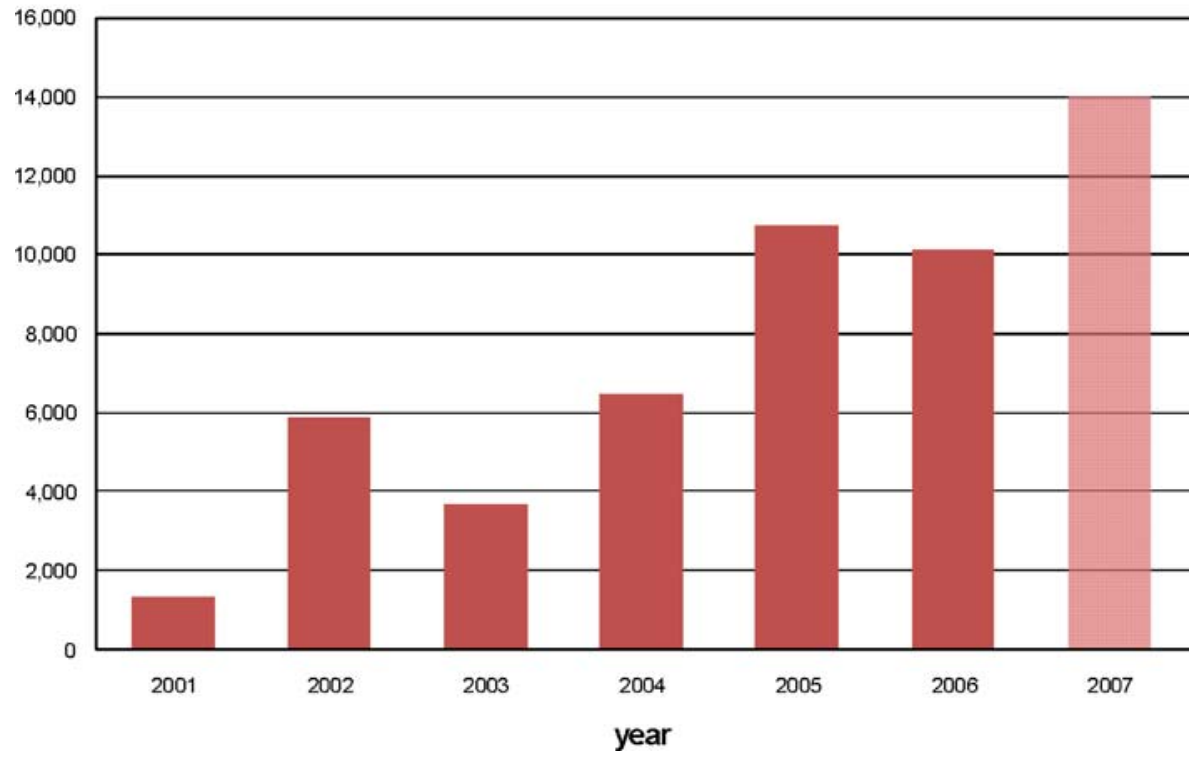

Fig. 3 Number of queries recorded for the online potato pedigree database over the last 6 years; 2007 data are a projection based on 6 months of visit statistics

sparked the idea to relaunch this data resource using a new and improved interface for providing access to the potato pedigree data. In January 2007, a new and updated database was launched at a new URL: http://potatodbase.dpw.wau.nl/potatopedigree using a new and more versatile server platform that allows the use of custom serverside scripts. Through the use of such scripts, search results may be processed and used for further data queries before they are presented to the user. The default output still presents the direct parentage of genotypes, but also presents a link to a more advanced script that will initiate a recursive search for the ancestry of the parents that are found and of grandparent ancestry, etc., up to a predefined generation from the original cultivar for which the database was queried. The script then returns a graphical representation of a conventional, branched pedigree scheme containing parents, grandparents, etc., as "nodes" in the tree diagram. Web technology allows the script to provide direct links from nodes (parents) present on these pedigree images to a search on more details regarding these nodes, and thus creates an interactive and fast way to further explore search results visible in the diagram. An example of the output generated by the recursive search algorithm is shown in Fig. 4, which presents the pedigree (up to five generations deep) for the newly released cultivar Citadel. The full pedigree of cv. Citadel has branches that go 19 generations deep.

The visualization script that underlies these images also tries to deal with ambiguities that are present in the data because of different genotypes that were given the same name. In the case of an ambiguity, a simple test on the year of release may rule out some of the possibilities, as an ancestor has to be older than any of its children (there may be exceptions when a genotype that has been used 


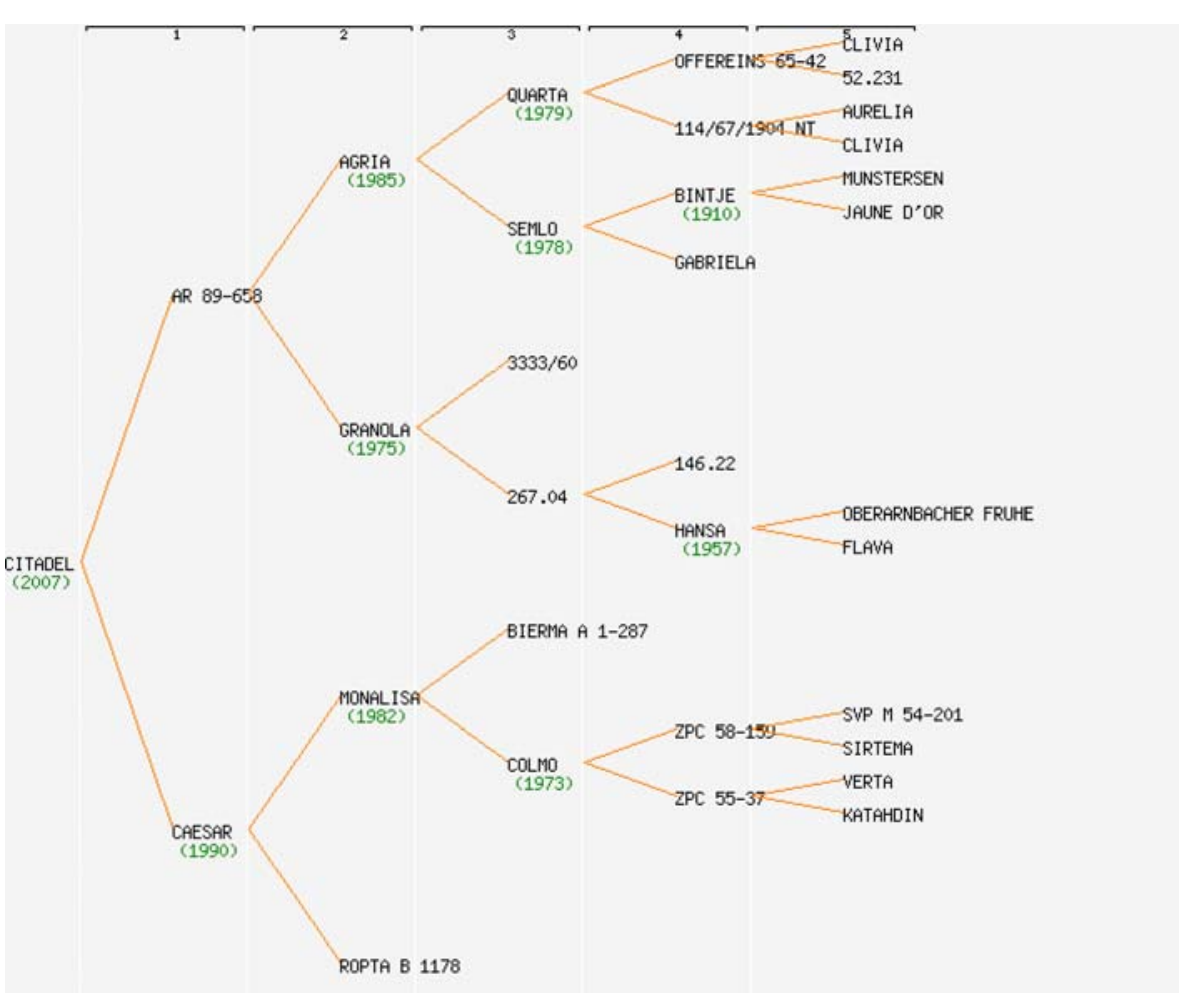

Fig. 4 Example pedigree diagram created within the pedigree database Web interface. In this example, a five-generation-deep pedigree diagram was requested for the recently released cultivar Citadel (2007). When known, the year of release of a cultivar/genotype is shown in brackets. When viewed online, these diagrams provide (point-and-click) links from cultivar names to further pedigree searches

as progenitor is released many years later, e.g., cv. Deltagold). If an ambiguity still cannot be resolved in this way, an arbitrary choice is made between the possible options, but the ambiguous ancestor is clearly marked in the diagram using a deviating color. The visualization script also provides parsing of special parentage compositions such as "mutant of X" or "synonym of Y," etc. In these cases, the recursive search will continue with the search for the parentage of $\mathrm{X}$ and $\mathrm{Y}$, respectively.

In addition to the simple search option, which takes only a genotype name as a key for searching, the potato pedigree Web site also provides a more advanced search option that allows users to search for (parts of) a name, country of origin, breeder, year of release, or a combination of these factors. This allows users to limit their search to specific subsets. Similarly to the simple search, the advanced search results provide links to a (backward) progeny search (reporting all genotypes that have in their pedigree the requested genotype as a parent) and to external resources at http://www.europotato.org with more information on phenotypic data. Fig. 5 shows an example of the report that resulted from an advanced search. In this 


\begin{tabular}{|c|c|c|c|c|c|c|c|}
\hline ID & NAME & crosscomb & orig & year & breeder code & breeder & reference \\
\hline 487 & $\begin{array}{l}\text { Offspring } \\
\text { ADRIANA }\end{array}$ & AGRIA $\times$ MORENE & FRA & 2003 & 91.16 .1 & $\begin{array}{l}\text { STATION DE RESERCH DU COMITE } \\
\text { NORD }\end{array}$ & 23 \\
\hline$\underline{552}$ & Offspring asd & & FRA & 2005 & G95TT061004 & GERMICOPA SA & \\
\hline$\underline{567}$ & $\begin{array}{l}\text { ALBANE } \\
\text { Offspring } 1 \mathrm{Ad} \text { - } \\
\text { ALDO }\end{array}$ & MIZEN $\times$ seedling & GB & 2003 & AD12 & A. DOBBIN & \\
\hline$\underline{570}$ & $\begin{array}{l}\text { Offspring Bad } \\
\text { ALERT }\end{array}$ & $\begin{array}{l}\text { SENSATION } \times \text { VE } \\
70-9\end{array}$ & $\mathrm{HOL}$ & 2005 & BVD 94-01 & G.J. BOUMA \& J.J. VAN DIJK & $12 / 06-07$ \\
\hline$\underline{595}$ & $\begin{array}{l}\text { Offspring } \\
\text { ALLIANS }\end{array}$ & $\begin{array}{l}185 / 88 / 359 \times E \\
87 / 66\end{array}$ & BRD & 2003 & $165 / 22 / 65 \mathrm{~B}$ & KARTOFFELZUCHT BOHM & 23 \\
\hline$\underline{663}$ & Offspring $\mathrm{Bad}$ & AGRIA $\times$ VK $69-491$ & $\mathrm{HOL}$ & 2005 & BH 96-273 & MAATSCHAP BOERHAVE VOF & \\
\hline$\underline{721}$ & $\begin{array}{l}\text { AMALIA } \\
\text { Offspring } \\
\text { ANDANTE }\end{array}$ & $1391.02 \times$ FILEA & BRD & 2004 & SA $95-045-3$ & SAKA-RAGIS & \\
\hline$\underline{735}$ & $\begin{array}{l}\text { Offspring } \mathrm{Xat} \text {. } \\
\text { ANETA }\end{array}$ & PONTO XF 3064/5 & $\mathrm{TCH}$ & 2003 & & $\begin{array}{l}\text { VESA VELHARTICE, SLECHTENI A } \\
\text { MNOZENI BRAMBOR, AS }\end{array}$ & \\
\hline$\underline{738}$ & $\begin{array}{l}\text { Offspring } \\
\text { ANGELA }\end{array}$ & $\begin{array}{l}138 / 86 / 4368 \times \\
654 / 86 / 6143\end{array}$ & BRD & 2003 & & KARTOFFELZUCHT BOHM & \\
\hline$\underline{757}$ & 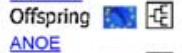 & $\begin{array}{l}\text { ROZEN } X \\
\text { MONALISA }\end{array}$ & FRA & 2003 & $\begin{array}{l}136.93 .1 \text { formerly } \\
\mathrm{CL}\end{array}$ & GROCEP & 23 \\
\hline$\underline{783}$ & $\begin{array}{l}\text { Offspring } \mathrm{XSA} \text {, } \\
\text { APOLLINE }\end{array}$ & & FRA & 2003 & G93TT028013 & GERMICOPA SA & 23 \\
\hline$\underline{880}$ & 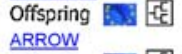 & $\begin{array}{l}\text { SOLARA } x \\
\text { FRESCO }\end{array}$ & $\mathrm{HOL}$ & 2004 & AR 93-84 & AGRICO RESEARCH BV & $12 / 06-07$ \\
\hline 898 & $\begin{array}{l}\text { Offspring } \\
\text { ASPIRANT }\end{array}$ & & BRD & 2004 & & EUROPLANT & \\
\hline$\underline{961}$ & $\begin{array}{l}\text { Offspring B: } \\
\text { AVALON }\end{array}$ & $\begin{array}{l}\text { ARTEMIS X } \\
\text { FRESCO }\end{array}$ & $\mathrm{HOL}$ & 2005 & LD 94-1001 & A.J. VAN DER LINDE & $12 / 07$ \\
\hline$\underline{962}$ & Offspring $\mathrm{Ba}$ [- $[\mathrm{c}]$ & KA $89-3516 x$ & $\mathrm{HOL}$ & 2005 & KA 95-1695 & KARNA & \\
\hline$\underline{965}$ & $\begin{array}{l}\text { AVANO } \\
\text { Offspring } \\
\text { AVARNA }\end{array}$ & $\begin{array}{l}\text { STABILO } \\
\text { KA } 89-3516 \times \\
\text { STABILO }\end{array}$ & $\mathrm{HOL}$ & 2005 & KA 95-1693 & AVERIS SEEDS & $12 / 06-07$ \\
\hline$\underline{966}$ & 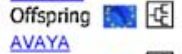 & $\begin{array}{l}\text { SERESTA } \times \text { VE 71- } \\
105\end{array}$ & $\mathrm{HOL}$ & 2005 & KA 96-0990 & AVERIS SEEDS & $12 / 07$ \\
\hline$\underline{968}$ & $\begin{array}{l}\text { Offspring Bad tect } \\
\text { AVENANCE }\end{array}$ & $\begin{array}{l}\text { MERCURY } \times \\
\text { FLORIJN }\end{array}$ & $\mathrm{HOL}$ & 2005 & KA 96-0692 & AVERIS SEEDS & $12 / 07$ \\
\hline 972 & $\begin{array}{l}\text { Offspring } \\
\text { AVENTRA }\end{array}$ & unknown & $\mathrm{HOL}$ & 2005 & KA 96-1334 & AVERIS SEEDS & $12 / 07$ \\
\hline$\underline{973}$ & $\begin{array}{l}\text { Offspring } \\
\text { AVERIA }\end{array}$ & $\begin{array}{l}\text { AM } 78-3704 \times \\
\text { KALIBER }\end{array}$ & $\mathrm{HOL}$ & 2004 & KA 93-0707 & AVERIS SEEDS & $12 / 04-07$ \\
\hline
\end{tabular}

Fig. 5 Part of a search report retrieved by performing an advanced search for all cultivars released between 2003 and 2005. The NAME column of this report contains direct links to (from left to right): a a search for offspring of the reported cultivar, b more information and phenotypic data at the URL http:// www.europotato.org, and $\mathbf{c}$ a dynamically created pedigree image. Clicking on column headers sorts the report on the selected field

example, a report was retrieved of all cultivars with data in the pedigree database that were released in 2003, 2004, and 2005.

\section{Discussion}

A central repository that focuses on potato pedigree information can be a valuable resource for anyone working in potato breeding or research. In this paper, we discussed the origin, data sources, and dissemination means of the potato pedigree database that was created over the course of 16 years. We have chosen to represent in this database only genotypes that have been released on the market as potato cultivars and any genotype that was used in the creation of such a cultivar. By not yet including other information on breeding lines and germplasm under development, we try to reduce the number of "orphans" (database entries that are unrelated to all other entries) and avoid "pollution" of the database with nonrelevant data. 
But can we be confident about data accuracy? First of all, we rely on the information provided by others, and cannot verify the administration of the breeders. Different sources of pedigree data sometimes report cultivars under slightly different names (spelling, translation) or report conflicting parental compositions. Inadvertent errors in pollination, seed harvest, or labeling may have yielded errors as well. The only argument we can offer is our 25 years of experience in evaluating source information that allows us to recognize and take care of typing errors, synonymous names, and breeder codes, for instance, by going back to the original or oldest information sources when this is possible, or by applying majority voting. We hope that increased efforts in the molecular genotyping of cultivars-for instance, by contemporary genomics projects - as well as increased phenotyping will shed more light on pedigree relationships and confirm existing data.

The problems originating from the existence of identically named entries in the database were already discussed. Different genotypes that are known under the same name may cause annoying (and expensive) problems of misunderstanding and miscommunication, even in current plant-breeding efforts. It is therefore highly recommended to check for the existence of a name before it is used to name a new cultivar. A central and easily searchable database, as described in this paper, may provide an additional valuable tool to check for the existence of cultivar names.

With this publication, we also invite breeders from any country to communicate pedigree information or to send their brochures to the corresponding author. Idealistically, we hope to receive an update with every newly released cultivar. Especially for pedigree information on progenitor lines, the current "dead ends," we rely on breeders willing to share the archives of their company or research institute.

\section{Availability}

The online potato pedigree database is a free Web resource. Users of this data resource are encouraged to quote this paper as a reference in any publication that describes work that has benefited from the existence of these data. The online potato pedigree database version 1 is still available at http:/www.dpw.wau.nl/pv/query.asp Version 2 is available at http://potatodbase.dpw.wau.nl/potatopedigree We are working on a new Web site and server that will also contain (a copy of) this database at http://www.plantbreeding.wur.nl

\section{Conclusions}

With the accumulation of potato pedigree data, and by providing access to these data in a versatile form over the Internet, the Laboratory of Plant Breeding of Wageningen University has provided the potato community with a valuable and useful resource. This resource will continue to be extended and updated on a regular basis. The authors would greatly appreciate communication of pedigree information on progenitors and cultivars that is lacking or erroneous in the database. 
Acknowledgements The research described in this paper was funded in part by the NWO financed program Phytoinformatics and by the Centre for BioSystems Genomics.

\section{References}

Baayen RP, Cochius G, Hendriks H, Meffert P, Bakker J, Bekker M,Van den Boogert PHJF, Stachewicz H, Van Leeuwen GCM (2006) History of potato wart disease in Europe - a proposal for harmonisation in defining Pathotypes. European J Plant Pathol 116:21-29. DOI 10.1007/s10658-006-9039-y

Brigneti G, Garcia-Mas J, Baulcombe DC (1997) Molecular mapping of the potato virus Y resistance gene $R y_{\text {sto }}$ in potato. Theor Appl Genet 94:198-203. DOI 10.1007/s001220050400

Busch (1889) Der Kartoffelbau. Hugo Voigt, Leipzig

Clark CF, Lombard PM (1946) Descriptions of and key to American potato varieties. USDA Circular No. 741 , p 50

Diehl R (1938) La pomme de terre. Paris, Inprimerie, Leipzig

Falconer DS, Mackay TFC (1996) Introduction to quantitative genetics (4th edn). Longman, Harlow

Flis B, Hennig J, Strzelczyk-Zyta D, Gebhardt C, Marczewski W (2005) The Ry- $f_{\text {sto }}$ gene from Solanum stoloniferum for extreme resistant to Potato virus $Y$ maps to potato chromosome XII and is diagnosed by PCR marker GP122 218 in PVY resistant potato cultivars. Mol Breeding 15(1):95-101. DOI 10.1007/s11032-004-2736-3

Gaut BS, Long AD (2003) The lowdown on linkage disequilibrium. The Plant Cell 15:1502-1506. DOI $10.1105 /$ tpc. 150730

Hämäläinen JH, Watanabe KN, Valkonen JPT, Arihara A, Plaisted RL, Pehu E, Miller L, Slack SA (1997) Mapping and marker-assisted selection for a gene for extreme resistance to potato virus Y. Theor Appl Genet 94(2):192-197. DOI 10.1007/s001220050399

Hämäläinen JH, Sorri VA, Watanabe KN, Gebhardt C, Valkonen JPT (1998) Molecular examination of a chromosome region that controls resistance to potato $\mathrm{Y}$ and A potyviruses in potato. Theor Appl Genet 96(8):1036-1043. DOI 10.1007/s001220050836

Hogen-Esch JA, Zingstra H, (1954, 1957, 1962, 1969, 1971/1972, 1973/1974) Geniteurslijst voor aardappelrassen. COA Wageningen

Joosten A, van der Woude K (1985) Geniteurslijst voor aardappelrassen. COA Wageningen

Joosten A $(1988,1991)$ Geniteurslijst voor aardappelrassen. COA Wageningen

Malosetti M, van der Linden CG, Vosman B, van Eeuwijk FA (2007) A mixed-model approach to association mapping using pedigree information with an illustration of resistance to Phytophthora infestans in potato. Genetics 175:879-889. DOI 10.1534/genetics.105.054932

Pushkarnath (1964) Potato in India-Varieties. Indian Council of Agricultural Research

Rafalski A (2002) Novel genetic mapping tools in plants: SNPs and LD-based approaches. Plant Sci 162:329-333. DOI 10.1016/S0168-9452(01)00587-8

Salaman RN (1926) Potato varieties. Cambridge University Press.

Salaman RN (1949) The history and social influence of the potato. Cambridge University Press

Sato M, Nishikawa K, Komura K, Hosaka K (2006) Potato virus $Y$ resistance gene, $R y_{\text {chc }}$, mapped to the distal end of potato chromosome 9. Euphytica 149(3):367-372. DOI 10.1007/s10681-006-9090-y

Schick R, Klinkowski M (1962) Die Kartoffel. VEB Deutscher Landwirtschaftsverlag

Simko I, Costanzo S, Haynes KG, Christ BJ, Jones RW (2004) Linkage disequilibrium mapping of a Verticillium dahliae resistance quantitative trait locus in tetraploid potato (Solanum tuberosum) through a candidate gene approach. Theor Appl Genet 108:217-224. DOI 10.1007/s00122-003-1431-9

Song Y-S (2004) Genetic marker analysis in potato for extreme resistance $\left(R y_{s t o}\right)$ to PVY and for chip quality after long term storage at $4{ }^{\circ} \mathrm{C}$. Dissertation Fakultät Wissenschaftszentrum Weihenstephan für Ernährung, Landnutzung und Umwelt, Technische Universität München

Song Y-S, Hepting L, Schweizer G, Hartl L, Wenzel G, Schwarzfischer A (2005) Mapping of extreme resistance to PVY $\left(R y_{\text {sto }}\right)$ on chromosome XII using anther-culture-derived primary dihaploid potato lines. Theor Appl Genet 111(5):879-887. DOI 10.1007/s00122-005-0010-7

Swiezynski KM, Haynes KG, Hutten RCB, Sieczka MT, Watts P, Zimnoch-Guzowska E (1997) Pedigree of European and North-American potato varieties. Plant Breed Seed Sci, Supplement to Vol 41 Number 1

Tinker NA, Deyl JK (2005) A curated database of oat pedigrees. Crop Sci 45:2269-2272. DOI 10.2135/ cropsci2004.0687 
Van Berloo R, Hutten RCB (2005) Peditree: Pedigree database analysis and visualization for breeding and science. J Heredity 96:465-468. DOI 10.1093/jhered/esi059

Yu J, Pressoir G, Briggs WH, Vroh Bi I, Yamasaki M, Doebley JF, McMullen MD, Gaut BS, Nielsen DM, Holland JB, Kresovich S, Buckler ES (2006) A unified mixed-model method for association mapping that accounts for multiple levels of relatedness. Nat Genet 38:203-208. DOI 10.1038/ng1702

Zingstra H, Scheijgrond W (1975/1976, 1977/1978, 1979/1980) Geniteurslijst voor aardappelrassen. COA Wageningen

Zingstra H (1981/1982) Geniteurslijst voor aardappelrassen 